\title{
Correction to: Control of Slag Carryover from the BOF Vessel During Tapping: BOF Cold Model Studies
}

\author{
ASHOK KAMARAJ, G.K. MANDAL, and G.G. ROY
}

https://doi.org/10.1007/s11663-019-01562-8

(c) The Minerals, Metals \& Materials Society and ASM International 2019

\section{Correction to: \\ Metallurgical and Materials Transactions B \\ February 2019, Volume 50, Issue 1, pp 438-458 \\ https://doi.org/10.1007/s11663-018-1432-3}

THE authors would like to correct the affiliations for this article. They appear correctly here.

Publisher's Note Springer Nature remains neutral with regard to jurisdictional claims in published maps and institutional affiliations.

ASHOK KAMARAJ and G.K. MANDAL are with the CSIRNational Metallurgical Laboratory (CSIR-NML), Jamshedpur 831 007, India and also with the Academy of Scientific and Innovative Research (AcSIR), Ghaziabad, 201 002, India. Contact emails: srhsbioboy@yahoo.co.in, ashokk@nmlindia.org G.G. ROY is with the Indian Institute of Technology, Kharagpur 721 302, India and also with the Academy of Scientific and Innovative Research (AcSIR), Ghaziabad, 201002 , India.

The original article can be found online at https://doi.org/10.1007/ s11663-018-1432-3.

Article published online March 28, 2019. 